\title{
The clinical features of pulmonary artery involvement in Takayasu arteritis and its relationship with ischemic heart diseases and infection
}

\author{
Hiroki Mukoyama ${ }^{1}$, Mirei Shirakashi ${ }^{1}$, Nozomi Tanaka ${ }^{1}$, Takeshi Iwasaki ${ }^{1}$, Toshiki Nakajima ${ }^{2}$, Hideo Onizawa ${ }^{3}$, \\ Hideaki Tsuji ${ }^{1}$, Koji Kitagori ${ }^{1}$, Shuji Akizuki ${ }^{1}$, Ran Nakashima ${ }^{1}$, Kosaku Murakami ${ }^{1}$, Masao Tanaka ${ }^{3}$, \\ Akio Morinobu and Hajime Yoshifuji ${ }^{*}$ (D)
}

\begin{abstract}
Background: Pulmonary artery involvement (PAI) in Takayasu arteritis (TAK) can lead to severe complications, but the relationship between the two has not been fully clarified.

Methods: We retrospectively investigated 166 consecutive patients with TAK who attended Kyoto University Hospital from 1997 to 2018. The demographic data, clinical symptoms and signs, comorbidities, treatments, and imaging findings were compared between patients with and without PAI. TAK was diagnosed based on the American College of Rheumatology Classification Criteria (1990) or the Japanese Clinical Diagnostic Criteria (2008). PAI was identified using enhanced computed tomography, magnetic resonance imaging, or lung scintigraphy.
\end{abstract}

Results: PAl was detected in $14.6 \%(n=24)$ of total TAK patients. Dyspnea ( $25.0 \%$ vs. $8.6 \% ; p=0.043)$, pulmonary arterial hypertension (PAH) (16.7\% vs. $0.0 \% ; p<0.001)$, ischemic heart disease (IHD) (29\% vs. 9.3\%; $p=0.018)$, respiratory infection (25.0\% vs. 6.0\%; $p=0.009$ ), and nontuberculous mycobacteria (NTM) infection (20.8\% vs. 0.8\%; $p<0.001$ ) were significantly more frequent, and renal artery stenosis ( $0 \% \mathrm{vs.} 17 \% ; p=0.007$ ) was significantly less frequent in TAK patients with PAI than in those without PAI. PAI and biologics were risk factors for NTM.

Conclusions: TAK patients with PAI more frequently have dyspnea, PAH, IHD, and respiratory infection, including NTM, than TAK patients without PAI.

Keywords: Takayasu arteritis, Pulmonary artery involvement, Ischemic heart diseases, Infection

\section{Introduction}

Takayasu arteritis (TAK) is an idiopathic vasculitis predominantly affecting the aorta and its branches. However, TAK can also affect the carotid, subclavian, renal, iliac, coronary, and pulmonary arteries (PA). Vessel wall

\footnotetext{
*Correspondence: yossii@kuhp.kyoto-u.ac.jp

'Department of Rheumatology and Clinical Immunology, Graduate

School of Medicine, Kyoto University, 54 Shogoin Kawahara-cho, Sakyo-ku, Kyoto 606-8507, Japan

Full list of author information is available at the end of the article
}

inflammation leads to arterial wall thickening, dilation, stenosis, and occlusion. PA involvement (PAI) occurs in $5.7-25.93 \%$ of all cases [1-10]. TAK with PAI is occasionally complicated with pulmonary hypertension $(\mathrm{PH})$, resulting in the risk of early mortality $[8,11]$. The early detection of PAI in TAK patients is important for preventing disease progression. However, as the disease is rare, the previously reported data, including several cohort studies, remains insufficient, and the clinical features of TAK with PAI are not fully clarified. Therefore, original author(s) and the source, provide a link to the Creative Commons licence, and indicate if changes were made. The images or other third party material in this article are included in the article's Creative Commons licence, unless indicated otherwise in a credit line to the material. If material is not included in the article's Creative Commons licence and your intended use is not permitted by statutory regulation or exceeds the permitted use, you will need to obtain permission directly from the copyright holder. To view a copy of this licence, visit http://creativecommons.org/licenses/by/4.0/. The Creative Commons Public Domain Dedication waiver (http://creativeco mmons.org/publicdomain/zero/1.0/) applies to the data made available in this article, unless otherwise stated in a credit line to the data. 
we retrospectively investigated the clinical features of TAK with PAI.

\section{Patients and methods}

The medical records of 186 consecutive patients with TAK who visited Kyoto University Hospital, Kyoto, Japan, from 1997 to 2018 were reviewed. Twenty patients were excluded due to insufficient information. The demographic data, clinical symptoms and signs, imaging findings, treatments, and comorbidities were reviewed and compared between TAK patients with and without PAI. This study was approved by the Ethics Committee of Kyoto University Graduate School and Faculty of Medicine (G412). All study procedures were performed following the Declaration of Helsinki principals. TAK was diagnosed based on the 1990 American College of Rheumatology Classification Criteria [12] or the 2008 Japanese Clinical Diagnostic Criteria [13]. PAI was screened using enhanced computed tomography (CT), magnetic resonance imaging (MRI), or lung scintigraphy and was defined as the presence of vascular involvement manifested as stenosis, occlusion, dilation, or aneurysm formation in either PA. Fever was defined as body temperature $\geq 38{ }^{\circ} \mathrm{C}$. Hypertension was defined by systolic hypertension of $\geq 140 \mathrm{mmHg}$ or diastolic hypertension of $\geq 90 \mathrm{mmHg}$. Blood pressure discrepancy between arms was defined as that of $\geq 10 \mathrm{mmHg}$. Ischemic heart disease (IHD) was defined as angina pectoris and myocardial infarction that could be confirmed on the medical record. All patients with pulmonary arterial hypertension $(\mathrm{PAH})$ were diagnosed using right heart catheterization (RHC), based on a mean PA pressure of $>20 \mathrm{mmHg}$ with a PA wedge pressure of $\leq 15 \mathrm{mmHg}$, a pulmonary vascular resistance of $>3.0$ Wood Unit, and exclusion of other types of PH [14]. Six systemic artery involvement subtypes were classified considering the classification criteria proposed by Hata et al. (Types I, IIa, IIb, III, IV, and V) [15]. Serious infection was defined as viral, bacterial, or fungal infections requiring hospitalization or intravenous antibiotics. Tuberculosis and nontuberculous mycobacteria (NTM) infections were also considered serious infections because they can cause significant disability and sequela. Respiratory infection was defined as a serious infection of respiratory systems, including pneumonia and NTM pulmonary disease. NTM pulmonary disease was diagnosed using criteria proposed by the American Thoracic Society/Infectious Disease Society of America in 2007 [16]. All lung lesions including PAI and NTM were confirmed by radiologists.

Continuous variables were presented as means and standard deviations, and Student's $t$ test was used to compare the groups. Qualitative variables were presented as numbers and percentages, and Fisher's exact test was used to compare the groups. Multivariate logistic regressions were used to detect factors independently associated with NTM infection. The data analysis was conducted using JMP ${ }^{\circledR} 14$ (SAS Institute Inc., Cary, NC, USA). Kaplan-Meier analysis was conducted using GraphPad Prism version 7.0b for Mac OS X, GraphPad Software, San Diego, CA, USA, www.graphpad. com. $P$ values less than 0.05 were considered statistically significant.

\section{Results}

Patients' backgrounds and clinical characteristics are presented in Table 1; 166 TAK patients were included. PAI was detected in $14.6 \%(n=24)$. Representative images of PAI are presented in Fig. 1. Of those with PAI, the mean age was $54.5 \pm 17.0$ years, duration from the onset was $20.7 \pm 14.6$ years, and the observation period was 7.8 \pm 6.8 years, which did not differ from patients without PAI. Dyspnea (25.0\% vs. $8.6 \% ; p=0.043)$, PAH $(16.7 \%$ vs. $0.0 \% ; p<0.001)$, and IHD ( $28.6 \%$ vs. $9.2 \% ; p=0.022)$ were significantly more frequent, and renal artery stenosis $(0.0 \%$ vs. $17.0 \% ; p=0.007)$ was significantly less frequent in TAK patients with PAI than in those without. Echocardiography was performed in all the TAK patients. In our hospital, RHC was performed when the peak tricuspid regurgitation velocity was $2.9 \mathrm{~m} / \mathrm{s}$ or higher [17], as possible, if there were no contraindications. Based on this criterion, 8/166 patients underwent RHC and 4/8 were proven to have PAH. Respiratory infection $(25.0 \%$ vs. $6.0 \% ; p=0.009)$ and NTM infection (20.8\% vs. $0.8 \% ; p$ $<0.001$ ) were significantly more frequent in TAK patients with PAI than in those without. In this study, all patients with NTM infection had pulmonary NTM disease, and none had extra-pulmonary NTM disease. Further, all patients had received immunosuppressive treatment when the infection was diagnosed (Table 2). Representative images of patients with NTM infection are presented in Fig. 2. The predictors of NTM in patients with TAK were analyzed by univariate analysis with the Cox proportional-hazards model, which showed that PAI and biologics were risk factors for NTM (Table 3). KaplanMeier graphs depict the rate of developing serious infection, respiratory infection, and NTM infection in Fig. 3. Based on the log-rank test, TAK patients with PAI were at a significantly higher risk of these infection than those without.

PAI angiographic features are presented in Table 4. Right PA lesions were more frequent than the left. Occlusion was the most frequent type of PAI. The systemic artery subtypes [15] are presented in Table 5. In all patients and patients without PAI, Type $\mathrm{V}$ was the most frequent, followed by Type I. Types IIa and IIb were more frequent in patients with PAI than in those without but 
Table 1 Patients' characteristics and clinical symptoms

\begin{tabular}{|c|c|c|c|}
\hline & $\operatorname{PAI}(n=24)$ & Without PAI $(n=142)$ & $P$ value \\
\hline \multicolumn{4}{|l|}{ Patients' characteristics } \\
\hline Duration from onset (years) & $20.7 \pm 14.6$ & $21.4 \pm 15.6$ & 0.835 \\
\hline Observation period (years) & $7.8 \pm 6.8$ & $9.1 \pm 6.8$ & 0.355 \\
\hline Onset age & $33.5 \pm 13.1$ & $30.1 \pm 15.8$ & 0.325 \\
\hline Age at surveillance & $54.5 \pm 17.0$ & $52.2 \pm 17.7$ & 0.564 \\
\hline Female & $22(91.7 \%)$ & $130(91.6 \%)$ & 1.000 \\
\hline \multicolumn{4}{|l|}{ Symptoms } \\
\hline \multicolumn{4}{|l|}{ Systemic manifestation } \\
\hline Fever & $2(9.5 \%)$ & $33(25.8 \%)$ & 0.163 \\
\hline General fatigue & $7(33.3 \%)$ & $54(42.5 \%)$ & 0.481 \\
\hline Hypertension & $8(38.1 \%)$ & $53(40.8 \%)$ & 1.000 \\
\hline \multicolumn{4}{|l|}{ Head and neck } \\
\hline Dizziness & $8(38.1 \%)$ & $48(37.2 \%)$ & 1.000 \\
\hline Headache & $7(33.3 \%)$ & $36(27.9 \%)$ & 0.610 \\
\hline Syncope & $0(0.0 \%)$ & $8(6.3 \%)$ & 0.602 \\
\hline \multicolumn{4}{|l|}{ Eyes } \\
\hline Eye symptoms & $4(20.0 \%)$ & $26(20.5 \%)$ & 1.000 \\
\hline Visual disorder & $2(9.5 \%)$ & $13(10.1 \%)$ & 1.000 \\
\hline \multicolumn{4}{|l|}{ Heart and lung } \\
\hline Dyspnea & $5(25.0 \%)$ & $11(8.6 \%)$ & 0.044 \\
\hline Chest compression & $6(30.0 \%)$ & $16(12.5 \%)$ & 0.082 \\
\hline Hemosputum & $1(4.8 \%)$ & $2(1.6 \%)$ & 0.368 \\
\hline Heart murmur & $8(40.0 \%)$ & $40(31.8 \%)$ & 0.455 \\
\hline Ischemic heart disease & $6(28.6 \%)$ & $12(9.2 \%)$ & 0.022 \\
\hline Aortic valve regurgitation & $12(57.1 \%)$ & $55(41.3 \%)$ & 0.236 \\
\hline $\mathrm{PAH}$ & $4(16.7 \%)$ & $0(0.0 \%)$ & $<0.001$ \\
\hline \multicolumn{4}{|l|}{ Upper limbs } \\
\hline Pulselessness & $5(23.8 \%)$ & $31(24.6 \%)$ & 1.000 \\
\hline BP discrepancies between arms & $5(25.0 \%)$ & $44(34.1 \%)$ & 0.610 \\
\hline Fatigue of upper limbs & $5(25.0 \%)$ & $41(32.3 \%)$ & 0.611 \\
\hline \multicolumn{4}{|l|}{ Aorta } \\
\hline Aortic aneurysm & $1(4.8 \%)$ & $14(10.9 \%)$ & 0.696 \\
\hline \multicolumn{4}{|l|}{ Kidney } \\
\hline Renal artery stenosis & $0(0.0 \%)$ & $22(18.5 \%)$ & 0.043 \\
\hline Renal disorder & $2(9.5 \%)$ & $18(13.9 \%)$ & 0.741 \\
\hline \multicolumn{4}{|l|}{ Infection } \\
\hline Serious infection & $7(29.2 \%)$ & $17(12.7 \%)$ & 0.059 \\
\hline Respiratory infection & $6(25.0 \%)$ & $8(6.0 \%)$ & 0.009 \\
\hline Nontuberculous mycobacterium & $5(20.8 \%)$ & $1(0.8 \%)$ & $<0.001$ \\
\hline \multicolumn{4}{|l|}{ Treatment } \\
\hline Glucocorticoid & $21(87.5 \%)$ & $110(77.5 \%)$ & 0.416 \\
\hline Maximum glucocortioid (PSL) & $31.1 \pm 3.2$ & $33.4 \pm 1.4$ & 0.508 \\
\hline Immunosuppressants & $6(26.1 \%)$ & $54(38.9 \%)$ & 0.351 \\
\hline Biologics & $5(22.7 \%)$ & $17(12.2 \%)$ & 0.206 \\
\hline GC only & $11(47.8 \%)$ & $55(39.6 \%)$ & 0.455 \\
\hline $\mathrm{GC}+\mathrm{IS}$ & $3(12.5 \%)$ & $37(26.1 \%)$ & 0.200 \\
\hline $\mathrm{GC}+$ biologics & $2(8.7 \%)$ & $1(0.7 \%)$ & 0.009 \\
\hline$G C+I S+$ biologics & $3(13.0 \%)$ & $15(10.8 \%)$ & 0.750 \\
\hline Antiplatelet therapy & $11(52.4 \%)$ & $86(68.8 \%)$ & 0.210 \\
\hline Anticoagulation therapy & $8(38.1 \%)$ & $21(17.1 \%)$ & 0.038 \\
\hline Cardiovascular surgery & $2(11.1 \%)$ & $33(25.8 \%)$ & 0.242 \\
\hline Catheter treatment & $3(15.8 \%)$ & $25(21.2 \%)$ & 0.764 \\
\hline
\end{tabular}

Data are expressed as mean $\pm S D$, or number (percentage). The difference of continuous variables was tested by Student's $t$ test, and that of qualitative variables was tested by Fisher's exact test. PAI pulmonary artery involvement, $P A H$ pulmonary arterial hypertension, $B P$ blood pressure, $P S L$ predonisolone (mg/day), GC glucocorticoid, IS immunosuppressants. The percentage is calculated as a ratio of the number of cases for which clinical information was available 


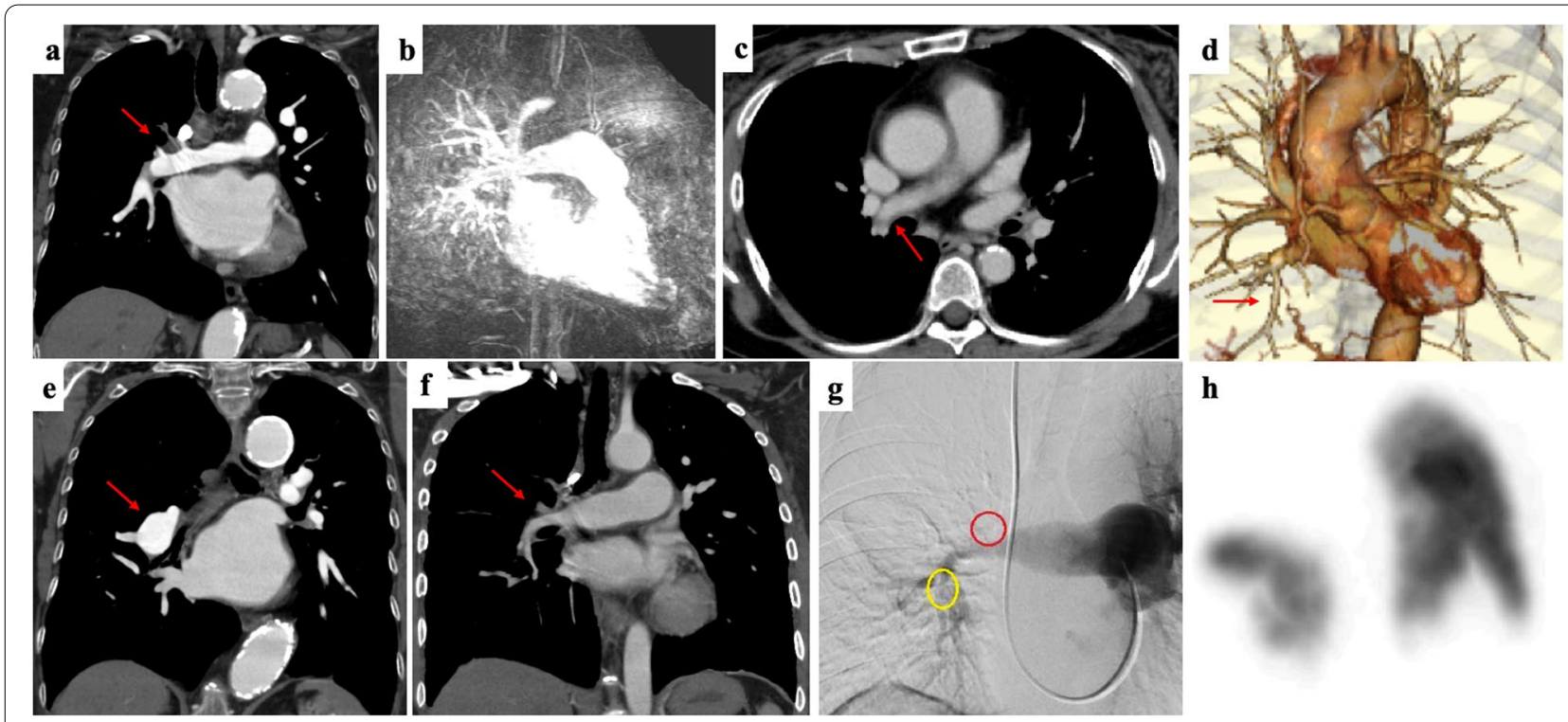

Fig. 1 Representative pulmonary artery involvement images. Occlusion of the right upper pulmonary artery branches on enhanced computed tomography (CT) (a). Occlusion of the left main pulmonary artery on magnetic resonance angiography (b). The right main pulmonary artery vessel wall thickness $(\mathbf{c})$ and stenosis of the lower pulmonary artery branches (d) on enhanced CT. Dilation of the right main pulmonary artery (e). Occlusion of the right pulmonary artery branches on enhanced CT (f) and angiography $(\mathbf{g})$. A perfusion defect in the right lung (h)

was statistically insignificant. Descending aorta involvement was less frequent in patients with PAI than patients without, and there were no Type IV patients or patients with renal artery stenosis with PAI.

Glucocorticoids were administered to 21 (87.5\%) patients with PAI and $110(77.5 \%)$ patients without PAI (Table $1 ; p=0.416$ ). Maximum glucocorticoid dose, immunosuppressant administration (40 patients were administered methotrexate, 27 azathioprine, 8 cyclophosphamide, 7 cyclosporines, 4 tacrolimus, and 1 mycophenolate mofetil), biologics administration (10 patients were administered tocilizumab, 7 infliximab, 3 ustekinumab, and 1 certolizumab pegol), a combination of the aforementioned therapies, antiplatelet therapy, cardiovascular surgery, and catheter treatment did not differ between the groups. Significantly more patients with PAI received anticoagulation therapy than patients without PAI $(n=8 ; 38.1 \%$ vs. $n=21 ; 17.1 \% ; p=0.038)$. Of those receiving anticoagulation therapy, 3 patients had deep venous thrombosis, 2 had atrial fibrillation, 1 had chronic heart failure, and 2 had only PAI. Patients who did not receive glucocorticoids, immunosuppressants, or biologics were considered to have an inactive disease.

Table 2 Clinical features and treatments of the patients complicate with NTM infection

\begin{tabular}{|c|c|c|c|c|c|c|c|c|}
\hline Case & PAI & Age, gender & Species & Type & $\begin{array}{l}\text { Treatment when } \\
\text { infection was diagnosed }\end{array}$ & $\begin{array}{l}\text { Maximum } \\
\text { PSL dose }\end{array}$ & $\begin{array}{l}\text { TAK disease duration } \\
\text { (months) at diagnosis } \\
\text { of NTM }\end{array}$ & Treatments for NTM \\
\hline 1 & Yes & $30 F$ & M. avium & FC & PSL 15 mg & 60 & 41 & $\begin{array}{l}\text { RFP, EB, CAM, SM, and } \\
\text { operation }\end{array}$ \\
\hline 2 & Yes & $55 F$ & M. avium & FC & $\begin{array}{l}\text { PSL } 7 \text { mg, TCZ } 162 \text { mg s.c./ } \\
\text { week }\end{array}$ & 40 & 241 & RFP, EB, CAM \\
\hline 3 & Yes & $31 \mathrm{~F}$ & M. avium & FC & $\begin{array}{l}\text { PSL } 5 \text { mg, MTX } 8 \text { mg/w, } \\
\text { TCZ } 8 \text { mg/kg DIV/4 weeks }\end{array}$ & 20 & 71 & $\begin{array}{l}\text { RFP, EB, CAM, SM, and } \\
\text { operation }\end{array}$ \\
\hline 4 & Yes & $72 \mathrm{~F}$ & M. intracellulare & NB & PSL $2.5 \mathrm{mg}$ & 20 & 592 & Observation \\
\hline 5 & Yes & $42 \mathrm{~F}$ & Not identified & NB & PSL $12.5 \mathrm{mg}$ & 30 & 69 & RFP, EB, CAM \\
\hline 6 & No & $64 \mathrm{~F}$ & M. intracellulare & NB & PSL 5 mg & 30 & 33 & Observation \\
\hline
\end{tabular}

PAI pulmonary artery involvement, NTM nontuberculous mycobacteria, PSL predonisolone (mg/day), TAK Takayasu arteritis, F female, M. avium mycobacterium avium, $M$. intracellulare mycobacterium intracellulare, FC fibrocavitary type, NB nodular/bronchiectatic type, PSL prednisolone, TCZ tocilizumab, MTX methotrexate, s.C subcutaneous infusion, DIV drip infusion in vein, RFP rifampicin, $E B$ ethambutol, CAM clarithromycin, $S M$ streptomycin 

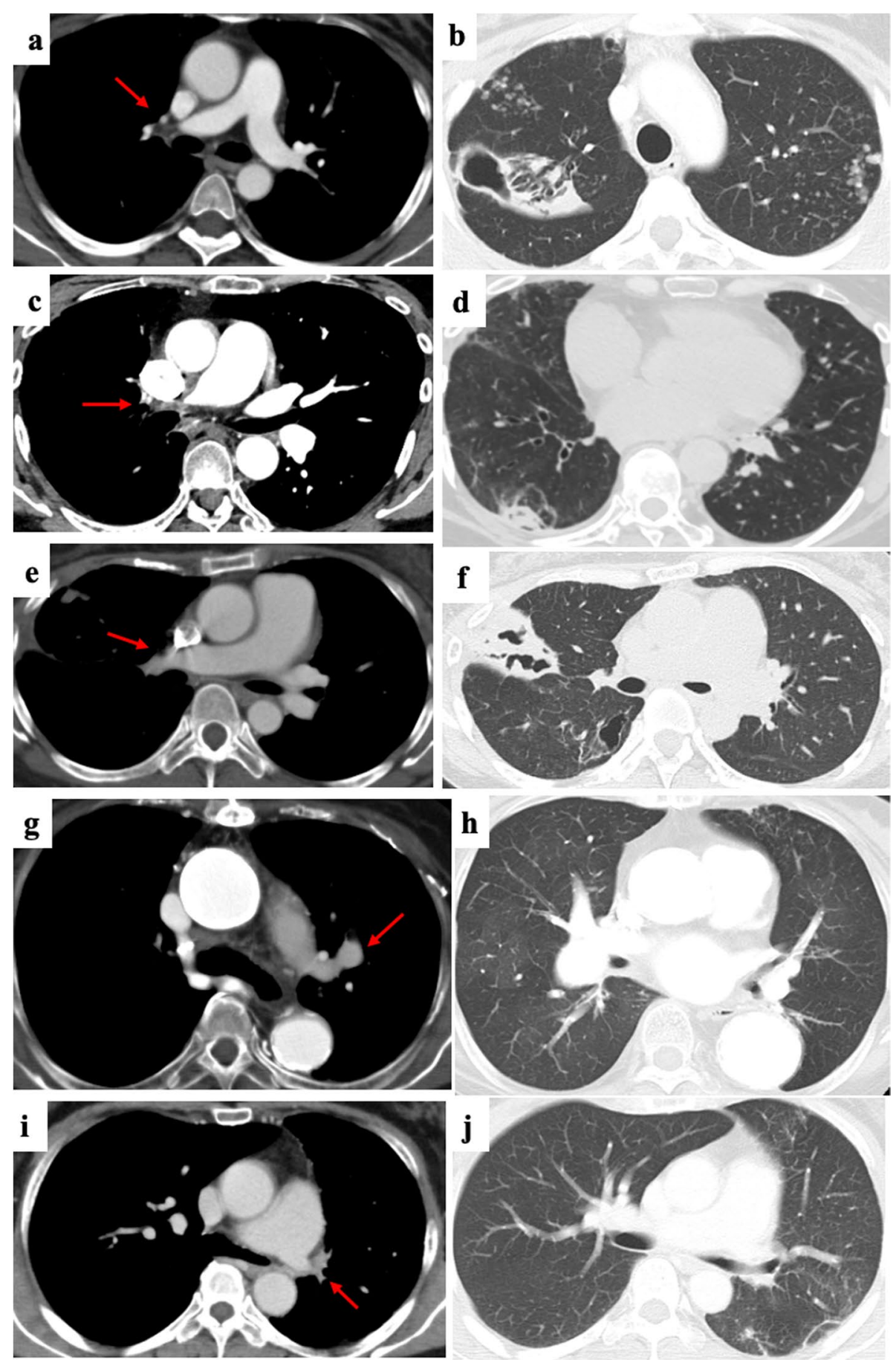

Fig. 2 Pulmonary artery involvement (PAI) and nontuberculous mycobacteria (NTM) disease imaging on computed tomography. Patient 1: occlusion of the right upper and middle pulmonary arterial branches (a) and a large opacity with a cavity in the right lower lobe and ill-defined nodules in bilateral lungs (b). Patient 2: occlusion of the right main pulmonary artery (c) and a large opacity in the right lower lobe (d). Patient 3: occlusion of the right upper and middle pulmonary artery branches (e) and a large opacity with a cavity in the right lung (f). Patient 4: dilation of the left pulmonary artery branches (g) and ill-defined nodules in the left upper lobe (h). Patient 5: occlusion of the left main pulmonary artery before developing NTM disease (i) and ill-defined nodules in the left lung (j). The left and right images of patients 2, 3, and 4 were taken simultaneously, since the previous images were not available. Patient 6 did not have PAI. Therefore, the images are not presented 
Table 3 Predictors of NTM infection in patients with TAK (Univariate analysis)

\begin{tabular}{lll}
\hline Variables & HR $(\mathbf{9 5} \% \mathbf{C l})$ & $\boldsymbol{P}$ value \\
\hline Age & $0.99(0.94-1.04)$ & 0.577 \\
Duration from onset & $0.99(1.00-1.01)$ & 0.104 \\
Maximum PSL dose & $1.00(0.95-1.05)$ & 0.982 \\
Immunosuppressants & $0.92(0.17-5.00)$ & 0.920 \\
Biologics & $8.44(1.67-42.67)$ & 0.010 \\
PAl & $34.86(4.07-298.53)$ & 0.001 \\
\hline
\end{tabular}

Univariate analysis with the Cox proportional-Hazards model for the risk for NTM infection. NTM nontuberculous mycobacterium, TAK Takayasu arteritis, PSL predonisolone $(\mathrm{mg} /$ day), PAl pulmonary artery involvement, $H R$ hazard ratio, $\mathrm{Cl}$ confidence interval

One patient with PAI and seven without PAI died during the observation period. The patient with PAI died due to a urinary tract infection. The patients without PAI died due to pneumonia $(n=3)$, gastrointestinal bleeding $(n$ $=2)$, carbon dioxide narcosis $(n=1)$, and sudden death with an unspecified cause $(n=1)$. Mortality did not differ between the groups based on Kaplan-Meier analysis (data not shown).

\section{Discussion}

PAI is a rare TAK complication. The effect of PAI has not been fully elucidated. PAI is reported with TAK in 5.7 to $25.93 \%$ [1-10]. In this study, the presence of PAI was $14.6 \%$, consistent with previous studies.

Our results indicated that TAK patients with PAI had dyspnea more frequently than those without PAI, consistent with the report by $\mathrm{He}$ et al. [7], suggesting that PAI should be considered when TAK patients complain of dyspnea. Further examination may find PAI sooner, potentially increasing the precautions taken for cardiovascular disease and respiratory infections, including NTM.

Wang et al. reported that right-sided PA lesions were more common than left-sided lesions in TAK patients with $\mathrm{PH}$ [18], and pulmonary arterial occlusions or near occlusions were found most frequently $(88.9 \%)$, followed by pulmonary arterial stenosis $(58.3 \%)$ and poststenotic dilation (27.8\%). In this study, right-sided PAI was

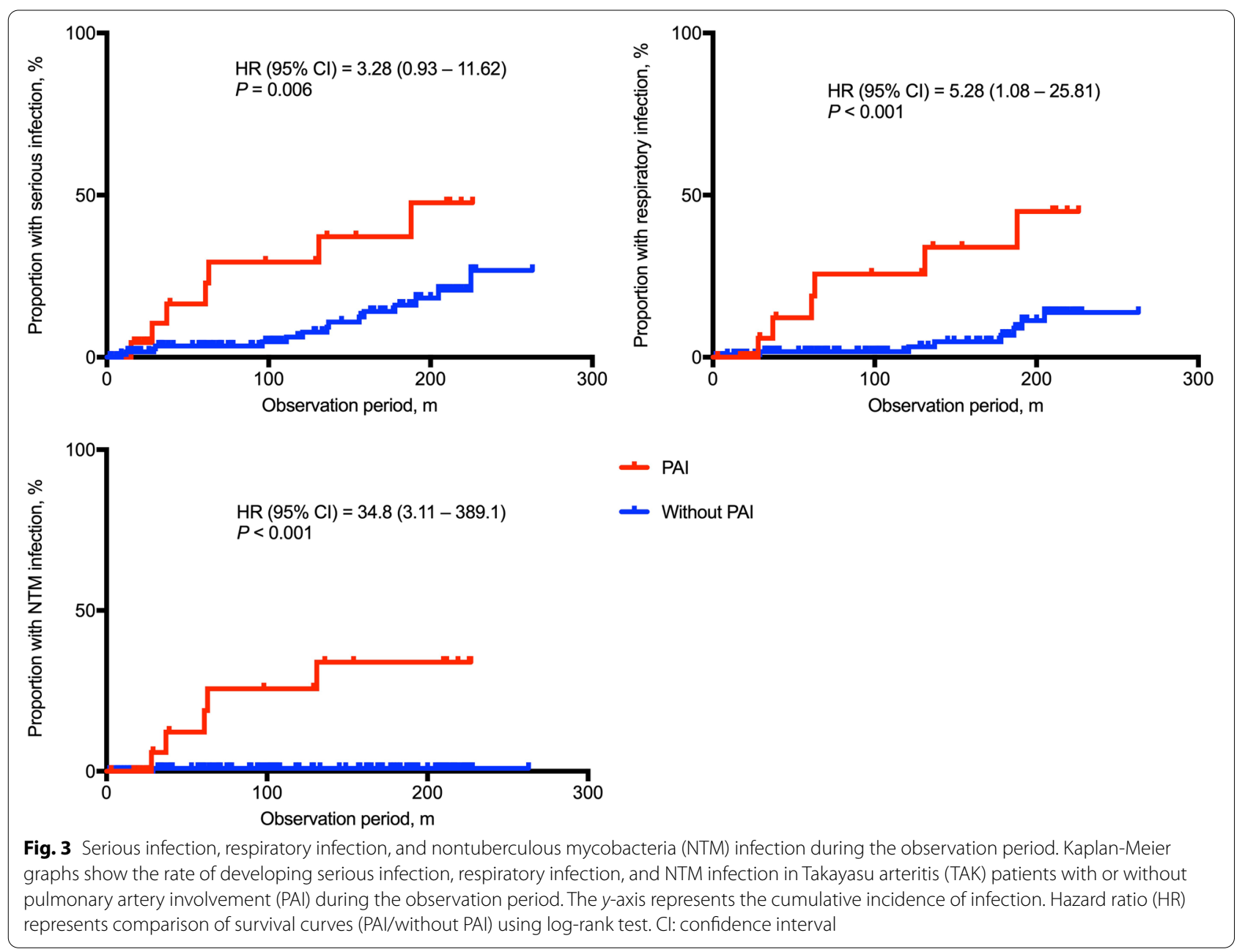


Table 4 Angiographic features of PAI

\begin{tabular}{ll}
\hline Laterality & $\begin{array}{l}\text { Right: } \mathbf{1 1}(\mathbf{4 5 . 8 \% ) , ~ L e f t : ~} \\
\mathbf{4}(\mathbf{1 6 . 7 \% )}, \text { Bilateral: } \mathbf{9} \\
\mathbf{( 3 7 . 5 \% )}\end{array}$ \\
\hline PA dilatation & $3(12.5 \%)$ \\
PA stenosis & $8(33.3 \%)$ \\
PA occlusion & $13(54.2 \%)$ \\
PA wall thickening & $2(8.3 \%)$ \\
Pulmonary thrombosis & $2(8.3 \%)$ \\
\hline
\end{tabular}

Data are expressed as numbers (percentage). PA pulmonary artery, PAI pulmonary artery involvement

Table 5 Classifications of vascular involvement

\begin{tabular}{llll}
\hline & Total $(\boldsymbol{n}=\mathbf{1 6 6})$ & PAI $(\boldsymbol{n}=\mathbf{2 4 )}$ & Without PAI $(\boldsymbol{n}=\mathbf{1 4 2})$ \\
\hline I & $37(26.4 \%)$ & $3(14.3 \%)$ & $34(28.6 \%)$ \\
Ila & $25(17.9 \%)$ & $7(33.3 \%)$ & $18(15.1 \%)$ \\
IIb & $14(10.0 \%)$ & $5(23.8 \%)$ & $9(7.6 \%)$ \\
III & $7(5.0 \%)$ & $1(4.8 \%)$ & $6(5.0 \%)$ \\
IV & $6(4.3 \%)$ & $0(0.0 \%)$ & $6(5.0 \%)$ \\
V & $51(36.4 \%)$ & $5(23.8 \%)$ & $46(38.7 \%)$ \\
\hline
\end{tabular}

Data are expressed as numbers (percentage). PAl pulmonary artery involvement

predominant, and occlusion (54.2\%) was the most frequent finding, followed by stenosis (33.3\%), and dilation (12.5\%), similar to Wang et al.

Our results suggest that the TAK subgroups have different vascular involvement preferences. For example, Types IIa and IIb were more frequent in patients with PAI than in those without, descending aorta involvement was less frequent in patients with PAI, and no PAI patient had Type IV TAK. Gribbons et al. reported that patients with TAK and giant cell arteritis could be divided into six clusters [19], one of which was more likely to have abdominal lesions and another to have bilateral subclavian and carotid artery lesions.

TAK with PAI is often complicated with $\mathrm{PH}$, resulting in a higher risk of early mortality $[8,11]$. Mechanical obstruction of the pulmonary vasculature is a major cause of $\mathrm{PH}$, and increased pulmonary vascular wall stiffness is also thought to be related [20]. In our study, PAH was a complication in $16.7 \%$ of TAK patients with PAI, and all PAH patients were diagnosed using RHC. This data regarding the PAH incidence in TAK patients is well-established because right heart overload detected by echocardiography does not always mean PAH. In our study, the presence of PAI did not lead to high mortality, perhaps because of the small sample size.

Using several imaging modalities to complement each other is preferable for diagnosis. First, traditional angiography was the gold standard for diagnosing TAK and detecting PAI [21, 22]. However, angiography is invasive and was replaced by $\mathrm{CT}$ and magnetic resonance angiography (MRA) [23]. CT and MRA also detect artery wall thickening [11, 24, 25]. Fluorodeoxyglucose-positron emission tomography is an even more sensitive modality to detect inflammation of artery, although it has lower power to detect lesions in small-diameter PAs [26, 27]. Pulmonary perfusion scintigraphy is also useful for PAI examinations. Perfusion defects indicate vascular occlusion, including small arteries that are sometimes not visible by CT [28-30]. Two patients were diagnosed with PAI by pulmonary perfusion scintigraphy in our study.

The treatment strategy for TAK patients with PAI is similar to that of TAK alone and includes immunosuppressive therapy, low-dose aspirin, and anticoagulative therapy. Reports suggest that the primary PAI treatment was immunosuppressive therapy [10]. Low-dose aspirin was used to prevent arterial ischemic events from TAK based on a single-center study that showed the efficacy of antiplatelet therapy [31]. Of the eight patients who received anticoagulation therapy, two patients received it for PAI and the others for deep venous thrombosis, atrial fibrillation, and chronic heart failure. No patients underwent PA stent implantation or surgery for PAs in the present study. Further research is needed to confirm the efficacy of antiplatelet or anticoagulant therapy for PAI.

To our knowledge, this is the first report to show an association between PAI and IHD. TAK may cause coronary artery stenosis, leading to myocardial infarction, heart failure, and sudden death [32]. It is reported that the coronary artery is affected in 10 to $60 \%$ of TAK patients [33-36]. Despite the high frequency of coronary artery lesions, only 5 to $20 \%$ of the cases are symptomatic [36], and most were detected by angiography or by cardiac MRI. Thus, the prevalence is likely to be underestimated. IHD in TAK patients is associated with a lower survival rate, and cardiac disease is the most chief cause of mortality in TAK patients [33,37]. An older age at TAK onset, a longer TAK course, and a higher rate of traditional factors associated with atherosclerosis are reported IHD risk factors [38].. This study suggests that PAI is also an IHD risk factor.

Further, this study addressed the relationship between PAI and NTM infection. Sugiyama et al. reported a case of NTM disease concomitant with a PA occlusion caused by TAK, causing a pulmonary cavity lesion [39]. There were six reported pulmonary infarction cases with TAK, including two of cavitary lesions with chronic aspergillosis infections [40-43]. The etiology of pulmonary infections and cavitation is multifactorial. Destroyed lung construction, such as bronchiectasis, bronchiolitis, and interstitial lung disease, are known risk factors for pulmonary NTM disease [44]. Cases complicated with 
NTM infection and chronic thromboembolic pulmonary hypertension have also been reported [45]. A non-perfused lung may result in the poor delivery of inflammatory cells to the inflammation site [42, 45]. However, NTM infection itself causes cavitation. Therefore, it is difficult to clarify what develops first, pulmonary cavitation or NTM infection. In our study, all patients with NTM pulmonary disease received glucocorticoids before onset. Immunosuppressive treatment and poor lung perfusion are considered the main causes of NTM infection, but NTM infection sometimes renders patients with severe sequela, limiting the treatment options and making TAK treatment difficult. Thus, the early diagnosis of this complication is important.

This study has several limitations. This is a retrospective single-center study with a relatively small sample size. The observation periods differed among patients, and some were lacking data. Further, the NTM incidence rate may not apply to other countries due to racial and socioeconomic differences. A prospective multi-center study is needed to investigate the clinical features of TAK with PAI.

In conclusion, this study demonstrated that dyspnea, PAH, IHD, and respiratory infection, including NTM, were more frequently observed in TAK patients with PAI than in TAK patients without PAI. The early diagnosis and monitoring of PAI complications are required.

\begin{abstract}
Abbreviations
CT: Computed tomography; IHD: Ischemic heart disease; MRI: Magnetic resonance imaging; NTM: Nontuberculous mycobacteria; PA: Pulmonary artery; PAH: Pulmonary arterial hypertension; PAl: Pulmonary artery involvement; PH: Pulmonary hypertension; RHC: Right heart catheterization; TAK: Takayasu arteritis.
\end{abstract}

\section{Acknowledgements}

We would appreciate Prof. Chikashi Terao in RIKEN for his cooperation in gene analysis, although the results were not included in the manuscript. We would like to thank Prof. Koichiro Ohmura in Kobe City Medical Center General Hospital and Prof. Tsuneyo Mimori of ljinkai Takeda General Hospital for supervising the study. We would like to express our deep gratitude to Prof. Hideyuki Kinoshita at Department of Community Medicine Supporting System, Graduate School of Medicine, Kyoto University for diagnosing and treating cases with pulmonary hypertension. We would like to thank Editage (www.editage. com) for English language editing.

\section{Authors' contributions}

HM collected, analyzed, and interpreted the data and composed the draft of the manuscript. HY and MS conceived the whole study design, interpreted the data, and modified the manuscript. TN and NT collected the data and performed the prototypic analyses. TI, HO, HT, KK, RN, SA, KM, MT, and AM contributed to study design, data interpretation, and manuscript composition. All authors read and approved the final manuscript.

\section{Funding}

Not applicable

\section{Availability of data and materials}

The dataset supporting the conclusions of this article is included within the article.

\section{Declarations}

\section{Ethics approval and consent to participate}

This study was approved by the Ethics Committee of Kyoto University Graduate School and Faculty of Medicine (G412). All study procedures were performed following the Declaration of Helsinki principles.

\section{Consent for publication}

Informed consent was obtained from each patient.

\section{Competing interests}

$\mathrm{HM}, \mathrm{MS}, \mathrm{NT}, \mathrm{TI}, \mathrm{TN}, \mathrm{HO}, \mathrm{HT}, \mathrm{KK}, \mathrm{SA}, \mathrm{RN}, \mathrm{KM}$, and AM claimed no COI for this work. MT has received research grants and/or speaker fees from AbbVie GK, Asahi Kasei Pharma Corp., Astellas Pharma Inc., Ayumi Pharmaceutical Corp., Bristol-Myers Squibb, Chugai Pharmaceutical Co., Ltd., Eisai Co., Ltd., Eli Lilly Japan K.K., Pfizer Inc., UCB Japan Co., Ltd., Janssen Pharmaceutical K.K., Mitsubishi Tanabe Pharma Corp., Novartis Pharma K.K., Taisho Pharma Co., Ltd. HY has received lecture fees from Chugai pharmaceuticals and AbbVie, and advisory fees from Janssen pharmaceuticals. Department of Advanced Medicine for Rheumatic Diseases is supported by two local governments in Japan (Nagahama City, Shiga and Toyooka City, Hyogo) and five pharmaceutical companies (Mitsubishi Tanabe Pharma Corp., Chugai Pharmaceutical Co., Ltd., Ayumi Pharmaceutical Corp., Asahi Kasei Pharma Corp. and UCB Japan Co., Ltd.).

\section{Author details}

'Department of Rheumatology and Clinical Immunology, Graduate School of Medicine, Kyoto University, 54 Shogoin Kawahara-cho, Sakyo-ku, Kyoto 606-8507, Japan. ${ }^{2}$ Tazuke Kofukai, Medical Research Institute, Kitano Hospital, Osaka, Japan. ${ }^{3}$ Department of Advanced Medicine for Rheumatic Diseases, Graduate School of Medicine, Kyoto University, Kyoto, Japan.

Received: 10 June 2021 Accepted: 9 November 2021

Published online: 03 December 2021

\section{References}

1. Watanabe Y, Miyata T, Tanemoto K. Current clinical features of new patients with Takayasu arteritis observed from cross-country research in Japan: age and sex specificity. Circulation. 2015;132:1701-9.

2. Bicakcigil M, Aksu K, Kamali S, Ozbalkan Z, Ates A, Karadag O, et al. Takayasu's arteritis in Turkey - clinical and angiographic features of 248 patients. Clin Exp Rheumatol. 2009;27(1 SUPPL. 52).

3. Lee GY, Jang SY, Ko SM, Kim EK, Lee SH, Han H, et al. Cardiovascular manifestations of Takayasu arteritis and their relationship to the disease activity: Analysis of 204 Korean patients at a single center. Int J Cardiol 2012;159:14-20. Available at: http://dx.doi.org/https://doi.org/10.1016/j. ijcard.2011.01.094.

4. Yang L, Zhang H, Jiang X, Zou Y, Qin F, Song L, et al. Clinical manifestations and longterm outcome for patients with Takayasu arteritis in China. J Rheumatol. 2014;41:2439-46.

5. Sari A, Sener YZ, Firat E, Armagan B, Erden A, Oksul M, et al. Pulmonary hypertension in Takayasu arteritis. Int J Rheum Dis. 2018;21:1634-9.

6. Kalfa M, Emmungil H, Musayev O, Soysal Gunduz O, Yilmaz Z, Inal V, et al. Frequency of pulmonary hypertension in transthoracic echocardiography screening is not increased in Takayasu arteritis: Experience from a single center in Turkey. Eur J Rheumatol. 2018;5:249-53.

7. He Y, Lv N, Dang A, Cheng N. Pulmonary artery involvement in patients with takayasu arteritis. J Rheumatol. 2020;47:264-72.

8. Direskeneli H. Pulmonary hypertension in Takayasu's arteritis: should be monitored closely. Int J Cardiol 2019;276:238-239. Available at: https:// doi.org/https://doi.org/10.1016/j.ijcard.2018.10.074.

9. Kong X, Ma L, Lv P, Cui X, Chen R, Ji Z, et al. Involvement of the pulmonary arteries in patients with Takayasu arteritis: a prospective study from a single centre in China. Arthritis Res Ther. 2020;22:1-10. 
10. Xi X, Du J, Liu J, Zhu G, Qi G, Pan L. Pulmonary artery involvement in Takayasu arteritis: a retrospective study in Chinese population. Clin Rheumatol. 2021:40:635-44.

11. Gong J, Yang Y, Ma Z, Guo X, Wang J, Kuang T, et al. Clinical and imaging manifestations of Takayasu's arteritis with pulmonary hypertension: a retrospective cohort study in China. Int J Cardiol. 2019;276:224-9.

12. Arend WP, Michel BA, Bloch DA, Hunder GG, Calabrese LH, Edworthy SM, et al. The American College of Rheumatology 1990 criteria for the classification of Takayasu arteritis. Arthritis Rheum. 1990;33(8):1129-34.

13. Guidelines JCS. Guideline for management of vasculitis syndrome (JCS 2008): Digest version. Circ J. 2011;75:474-503.

14. Simonneau G, Montani D, Celermajer DS, Denton CP, Gatzoulis MA, Krowka M, et al. Haemodynamic definitions and updated clinical classification of pulmonary hypertension. Eur Respir J 2019;53. Available at: http://dx.doi.org/https://doi.org/10.1183/13993003.01913-2018.

15. Hata A, Noda M, Moriwaki R, Numano F. Angiographic findings of Takayasu arteritis: new classification. Int J Cardiol 1996;54:S155-S163. Available at: http://dx.doi.org/https://doi.org/10.1016/S0167-5273(96) 02813-6.

16. Griffith DE, Aksamit T, Brown-Elliott BA, Catanzaro A, Daley C, Gordin F, et al. An official ATS/IDSA statement: diagnosis, treatment, and prevention of nontuberculous mycobacterial diseases. Am J Respir Crit Care Med. 2007;175:367-416.

17. Galiè N, Humbert M, Vachiery JL, Gibbs S, Lang I, Torbicki A, et al. 2015 ESC/ERS Guidelines for the diagnosis and treatment of pulmonary hypertension. Eur Heart J. 2016;37:67-119.

18. Wang X, Dang A, Chen B, Lv N, Liu Q. Takayasu arteritis-associated pulmonary hypertension. J Rheumatol. 2015;42:495-503.

19. Gribbons KB, Ponte C, Carette S, Craven A, Cuthbertson D, Hoffman GS, et al. Patterns of arterial disease in Takayasu arteritis and giant cell arteritis. Arthritis Care Res. 2020:72:1615-24.

20. Lee SD, Kim DS, Shim TS, Lim CM, Koh Y, Kim WS, et al. Nitric oxide and molsidomine in the management of pulmonary hypertension in Takayasu's arteritis. Chest 2001;119:302-307. Available at: http://dx.doi. org/https://doi.org/10.1378/chest.119.1.302.

21. Lupi E, Sanchez G, Horwitz S, Gutierrez E. Pulmonary artery involvement in Takayasu's arteritis. Chest. 1975;67:69-74.

22. Yamada I, Shibuya H, Matsubara O, Umehara I, Makino T, Numano F, et al. Pulmonary artery disease in Takayasu's arteritis: angiographic findings. Am J Roentgenol. 1992;159:263-9.

23. Dejaco C, Ramiro S, Duftner C, Besson FL, Bley TA, Blockmans D, et al. EULAR recommendations for the use of imaging in large vessel vasculitis in clinical practice. Ann Rheum Dis. 2018;77(5):636-643.

24. Tanigawa K, Eguchi K, Kitamura Y, Kawakami A, Ida H, Yamashita S, et al. Magnetic resonance imaging detection of aortic and pulmonary artery wall thickening in the acute stage of Takayasu arteritis. Improvement of clinical and radiologic findings after steroid therapy. Arthritis Rheum. 1992;35:476-80.

25. Jin SA, Lee JH, Park JH, Oh JK, Kim MS, Park YK, et al. Endovascular treatment in a patient with left main coronary and pulmonary arterial stenoses as an initial manifestation of Takayasu's arteritis. Hear Lung Circ 2015;24:e26-e30. Available at: http://dx.doi.org/https://doi.org/10.1016/j. hlc.2014.09.007.

26. Kusunose K, Yamada H, Tomita N, Nishio S, Niki T, Yamaguchi K, et al. Serial imaging changes during treatment of Takayasu arteritis with pulmonary artery stenosis. Int J Cardiol 2011;148:e47-e50. Available at: http://dx.doi. org/https://doi.org/10.1016/j.ijcard.2009.02.036.

27. Addimanda O, Spaggiari L, Pipitone N, Versari A, Pattacini P, Salvarani C. Pulmonary artery involvement in takayasu arteritis. PET/CT versus CT angiography. Clin Exp Rheumatol. 2013;31:4-5.

28. Castellani M, Vanoli M, Cali G, Bacchiani G, Origgi L, Reschini E, et al. Ventilation-perfusion lung scan for the detection of pulmonary involvement in Takayasu's arteritis. Eur J Nucl Med. 2001;28:1801-5.

29. Mekinian A, Lambert M, Huglo D, Devos P, Mirault T, Steinling M, et al. Pulmonary perfusion scintigraphy: a tool to detect the presence of pulmonary artery involvement in Takayasu's arteritis. Press Medicale. 2012:41(2):e37-42.

30. Yang J, Peng M, Shi J, Zheng W, Yu X. Pulmonary artery involvement in Takayasu's arteritis: diagnosis before pulmonary hypertension. BMC Pulm Med. 2019;19:1-9.
31. de Souza AWS, Machado NP, Pereira VM, Arraes AED, Reis Neto ET, Mariz $\mathrm{HA}$, et al. Antiplatelet therapy for the prevention of arterial ischemic events in takayasu arteritis. Circ J. 2010;74:1237-41.

32. Subramanyan R, Joy J, Balakrishnan KG. Natural history of aortoarteritis (Takayasu's disease). Circulation. 1989;80:429-37.

33. Versini M, Tiosano S, Sharif K, Mahroum N, Watad A, Comaneshter D, et al. Association between Takayasu arteritis and ischemic heart disease: a cohort study. Mediterr J Rheumatol. 2019;30:171

34. Comarmond C, Cluzel P, Toledano D, Costedoat-Chalumeau N, Isnard $\mathrm{R}$, Gaudric J, et al. Findings of cardiac magnetic resonance imaging in asymptomatic myocardial ischemic disease in Takayasu arteritis. Am J Cardiol 2014;113:881-887. Available at: http://dx.doi.org/https://doi.org/ 10.1016/j.amjcard.2013.11.045.

35. Park SJ, Kim HJ, Park H, Hann HJ, Kim KH, Han S, et al. Incidence, prevalence, mortality and causes of death in Takayasu arteritis in Korea - a nationwide, population-based study. Int J Cardiol 2017;235:100-104. Available at: http://dx.doi.org/https://doi.org/10.1016/j.ijcard.2017.02.086.

36. Miloslavsky E, Unizony S. The heart in vasculitis. Rheum Dis Clin North Am. 2014;40:11-26.

37. Li J, Zhu M, Li M, Zheng W, Zhao J, Tian X, et al. Cause of death in Chinese Takayasu arteritis patients. Medicine (Baltimore). 2016;95(27):e4069.

38. Wang Y, Jia SJ, Zhou Y, Li J, Zhao X, Zhao QM, et al. A study on the risk factors of coronary artery disease in patients with Takayasu arteritis. J Thorac Dis. 2020;12:2031-8.

39. Sugiyama T, Kawaguchi K, Usami N, Yokoi K. Nontuberculous mycobacterial disease concomitant with a pulmonary artery occlusion caused by Takayasu's arteritis. Gen Thorac Cardiovasc Surg. 2017:65:418-21.

40. Toledano K, Guralnik L, Lorber A, Ofer A, Yigla M, Rozin A, et al. Pulmonary arteries involvement in Takayasu's arteritis: two cases and literature review. Semin Arthritis Rheum 2011;41:461-470. Available at: http:// dx.doi.org/https://doi.org/10.1016/j.semarthrit.2011.06.001.

41. Elsasser $S$, Solèr M, Bolliger CT, Jäger K, Steiger U, Perruchoud AP. Takayasu disease with predominant pulmonary involvement. Respiration. 2000;67:213-5.

42. Ichi NJ, Ito S, Terada M, Saitoh Y, Ichi IK, Nakano M, et al. Pulmonary artery involvement in Takayasu's arteritis with lung infarction and pulmonary aspergillosis. J Clin Rheumatol. 2002;8:260-4 Available at: https://pubmed.ncbi.nlm.nih.gov/17041382/. Accessed February 12, 2021.

43. Nakamura T, Hayashi S, Fukuoka M, Sueoka N, Nagasawa K. Pulmonary infarction as the initial manifestation of Takayasu's arteritis. Intern Med. 2006; $45: 725-8$

44. Marras TK, Mehta M, Chedore P, May K, Al HM, Jamieson F. Nontuberculous mycobacterial lung infections in Ontario, Canada: clinical and microbiological characteristics. Lung. 2010;188:289-99.

45. Kuroda F, Tanabe N, Igari H, Sakurai T, Sakao S, Tada Y, et al. Nontuberculous mycobacterium diseases and chronic thromboembolic pulmonary hypertension. Intern Med. 2014;53:2273-9.

\section{Publisher's Note}

Springer Nature remains neutral with regard to jurisdictional claims in published maps and institutional affiliations. 